\title{
Trends in Road Traffic Deaths in Yazd, Iran, 2004 - 2010
}

\author{
Mohsen Mirzaei, ${ }^{1}$ Mahboobahsadat Mirzadeh, ${ }^{2}$ Hossein Shogaei Far, ${ }^{3}$ and Mojtaba Mirzaei ${ }^{4,}$ \\ ${ }^{1}$ Department of Community Medicine, Health Monitoring Research Center, Shahid Sadoughi University of Medical Sciences, Yazd, IR Iran \\ ${ }^{2}$ Department of Internal Medicine, Shahid Sadoughi University of Medical Sciences, Yazd, IR Iran \\ ${ }^{3}$ Health Center of Yazd Province, Shahid Sadoughi University of Medical Sciences, Yazd, IR Iran \\ ${ }^{4}$ Tehran University of Medical Sciences and Health Services, Tehran, IR Iran \\ "Corresponding author: Mojtaba Mirzaei, Tehran University of Medical Sciences and Health Services, Tehran, IR Iran, Tel/Fax:+989132595430. E-mail: \\ mojtaba.mirzaei.87@gmail.com
}

Received 2015 April 25; Revised 2015 December 23; Accepted 2015 December 27.

\begin{abstract}
Background: Road traffic deaths are a considerable public health problem and a major source of lost financial and human resources. Most mortality occurs in low- and middle-income countries.

Objectives: This study aimed to measure road traffic fatality rates and years of lost life, and also to depict a view of trends in road traffic deaths from 2004 to 2010 in Yazd city, a province in central Iran.

Materials and Methods: This retrospective case study analyzed road traffic deaths that were classified under the V01 - V99 codes of the ICD-10 in Yazd province from March 2004 to March 2010, using data that were collected from the death registration system of the Yazd province health center. Cases were classified according to age, sex, time of year, and residence (urban vs. rural). Years of lost life and road fatality rate per 100,000 people were calculated. Data were analyzed using chi-square test and ANOVA with SPSS 16.

Results: During the seven-year period of this study, 3,028 people in Yazd province died due to road traffic accidents (9.1\% of total deaths in the province). Most deaths occurred among people aged 20-24 (15\%), men (82.7\%), and urban residents (82.6\%). Total years of lost life (YLL) were 73,875 (60,337 and 13,489 in men and women, respectively). The road traffic fatality rate per 100,000 was 47.6 in 2004 and 37.6 in 2010 . In the study period, the rate of traffic fatalities decreased for men (from 77.9 to 68.5) but this is not the case for women (from 14.8 to 19.2). Road traffic deaths peaked every summer.

Conclusions: Despite the overall reduction trend, the road traffic fatality rate in Yazd province is still alarmingly high compared to national and global data. In addition, the female population shows increasing death rates. These findings can serve as a basis for health care professionals and policymakers to conduct preventive measures, especially during summer, and plan specifically for reducing fatalities in the female population.
\end{abstract}

Keywords: Traffic, Accidents, Mortality, Trends, Years of Potential Life Lost

\section{Background}

Road traffic injuries are one of the major factors affecting public health in the world. Worldwide, road accidents cause the death of about 1.2 million people annually and are estimated to become the 3rd leading cause of deaths by 2020 . This high mortality rate is not distributed evenly. Eighty-five to ninety percent of deaths due to road injuries and years of lost life occur in low-and middle-income countries despite higher vehicle ownership rates in developed countries (1-4).

In terms of economics, road traffic mortality is a major source of expense and loss of human resources. It is estimated that with every road traffic death, 15 and 70 people will need hospitalization and outpatient treatment respectively. The total cost of mortality and morbidity due to road traffic injuries in the eastern Mediterranean area is estimated at $\$ 7.4$ billion annually $(1,5,6)$.

Despite the possibilities for the reduction of road traffic deaths that has been reported in 88 countries, only 28 countries (with $7 \%$ of the world's population) have legis- lated adequately for controlling all 5 important risk factors of road injuries (i.e. speed limit, driving under the influence of alcohol, use of a seat belt, use of a helmet, and children's car seats.) Iran has regulations in only two of these areas: the use of seat belts and motorcycle helmets $(7,8)$.

Iran's road traffic fatality rate per 100,000 people was 22.1 in 1997, and increased to 40.5 in 2005 . In that year, Iran had the highest rate of road traffic deaths among all countries that collect reliable data. This increasing trend stopped in that year; however, the rate is still unacceptably high. One factor which may exacerbate the situation is the growing number of vehicles in Iran. Vehicle ownership in Iran is estimated to grow by about 1.5 million annually, which will probably cause the increase of road traffic deaths in absence of stricter legislation and police control (6, 9-11).

Yazd province is located in the center of Iran, and in 2006 and 2011 the population was 990,818 and 1,074,428 respectively. This province has the highest rate of vehicle ownership per family in Iran (12).

Previous studies on this subject did not investigate

Copyright ( $)$ 2016, Kashan University of Medical Sciences. This is an open-access article distributed under the terms of the Creative Commons Attribution-NonCommercial 4.0 International License (http://creativecommons.org/licenses/by-nc/4.0/) which permits copy and redistribute the material just in noncommercial usages, provided the original work is properly cited. 
data drawn from a large population, and lacked analyses of trends in road traffic deaths in consecutive years and calculations of years of life lost (YLL).

\section{Objectives}

In this study we investigated the total numbers of road traffic deaths, the road fatality rate per 100,000 people, and YLL over a seven-year period in Yazd province, the province with the most vehicles per family in Iran.

\section{Materials and Methods}

This was a descriptive case study that investigated road traffic deaths over a seven-year period retroactively. Our study population consisted of those who died due to road injuries in Yazd province between March 2004 and March 2010.

We collected our data from the death registration system of the health center in Yazd province. This system is based on data from different sources. Local health center doctors register and report deaths in their area each month using standard forms. In the international classification of diseases (ICD-10), road traffic injuries are classified under the codes V01 - V99. The provided list of deaths under specific codes was compared to reports of deaths from the national organization for civil registration and forensic department, as well as hospitals and cemeteries. Repeated items were omitted based on similarity in the victim's name and father's name, time of death, and ID number. If different causes of death were reported for the same person, we prioritized data for entering into our analysis based on reported source according to the following order: forensic department, hospital, and then local health centers. When we encountered missing or inaccurate codes in our registry, the death registry coordinator tried to revise this by calling and interviewing the responsible doctor and obtaining a verbal autopsy summary. Deceased residents of other provinces were excluded. Data on the estimated population in these years were collected from the Yazd province health center's database. Censuses were carried out by the national organization for civil registration in 1996, 2006 and 2011. In rural areas vital horoscopes' data were used to calculate the population in the years before and after national censuses. In urban areas, population was estimated by growth rate in these years. In Yazd province, the integrated health network was established in 1989, and the death registration system has been running since 2000.

Since death records include sensitive information, we analyzed the data anonymously and strongly protected information with regard to ethical considerations. We used
SPSS version 16 for analyzing our data. Descriptive statistics, including means with confidence intervals, were calculated. Road traffic fatality rate per 100,000 people and YLL in each year and age group were extracted. Chi square tests were used for comparing mortality between categorical variables. P values less than 0.05 were considered significant for all tests.

We calculated YLL values using the following formula, which is based on the methodology of the disability adjusted life year(DALY) index in the global burden of disease study from 2003 with world health organization (WHO) standard life expectancies $(13,14)$.

$\operatorname{YLL}(3.1)=\mathrm{N} \mathrm{Ce}(\mathrm{ra}) /(\beta+\mathrm{r}) 2[\mathrm{e}-(\beta+\mathrm{r})(\mathrm{L}+\mathrm{a})[-(\beta+\mathrm{r})(\mathrm{L}$ $+\mathrm{a})-1]-\mathrm{e}-(\beta+\mathrm{r}) \mathrm{a}[-(\beta+\mathrm{r}) \mathrm{a}-1]]$

Where:

$\mathrm{N}$, Number of deceased with a certain age and gender; L, WHO Standard life expectancy of the deceased at the same certain age and gender; r, Rate of discount equal to 0.03; $\beta$, Contractual rate in the calculation of age value equal to $0.04 ; \mathrm{C}$, Constant number equal to 0.1658 .

\section{Results}

Our study showed that during this seven-year period, 3,028 people in Yazd province died because of road injuries. This accounts for 9.1\% of all deaths in this time period. The percentage of deaths in Yazd province due to road accidents has increased from $9.29 \%$ in 2004 to $10.19 \%$ in 2005 ; it then decreased to $7.78 \%$ in 2010 . The road fatality rate in our study decreased from 47.6 per 100,000 in 2004 to 37.6 in 2010. The number of deaths and mortality rate in each year is shown in Table 1.

The mean age of victims in our study was $37.28 \pm 22.17$ (male: $37.13 \pm 21.59$ and female $37.95 \pm 24.52$ ) and the median age was 31 (male: 31 and female: 35 ). The most affected age group was those aged 20 - 24 (14.8\% of all mortality). However, the highest road traffic fatality rate per 100,000 people exists in people over age 60 (Figure 1).

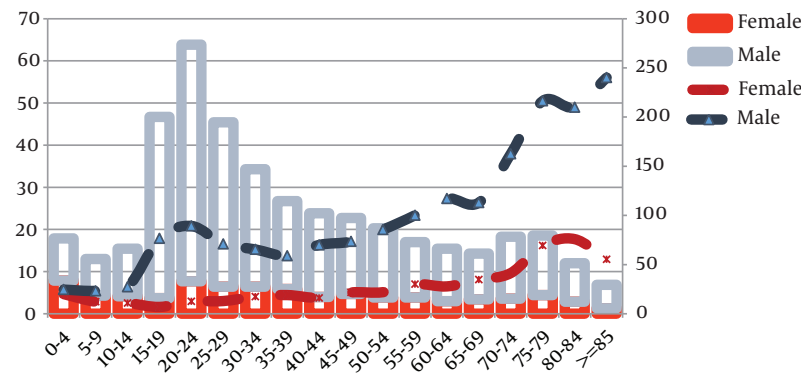

Figure 1. Average number of road traffic deaths/year and average road traffic fatality rate per 100,000 from 2004 to 2010 in Yazd Province, Iran, classified by age group 
Table 1. Road Traffic Deaths, Mortality Rate and Years of Lost Life in the Seven-Year Period From 2004 to 2010 in Yazd Province, Iran

\begin{tabular}{|c|c|c|c|c|c|c|c|c|}
\hline \multirow[t]{3}{*}{ Year } & \multirow[t]{3}{*}{ Deaths $^{\mathrm{a}}$} & \multicolumn{5}{|c|}{ Mortality Rate Per 100,000 } & \multicolumn{2}{|c|}{ Years of Lost Life } \\
\hline & & \multicolumn{2}{|c|}{ Sex } & \multicolumn{2}{|c|}{ Place } & \multirow[t]{2}{*}{ Total } & \multirow[t]{2}{*}{ Num. } & \multirow[t]{2}{*}{ Per 100,000 } \\
\hline & & Male & Female & Urban & Rural & & & \\
\hline 2004 & $441(9.29)$ & 77.9 & 14.8 & 47 & 49.7 & 47.6 & 11122 & 1199 \\
\hline 2005 & $490(10.19)$ & 82.6 & 19.7 & 52.1 & 53 & 52.3 & 12434 & 1326 \\
\hline 2006 & $480(10.18)$ & 80.4 & 18.6 & 50.8 & 49.8 & 50.6 & 11671 & 1230 \\
\hline 2007 & $438(9.3)$ & 70.6 & 18.5 & 47.6 & 36.6 & 45.5 & 10888 & 1131 \\
\hline 2008 & $405(8.4)$ & 65.1 & 16.3 & 41.4 & 42.5 & 41.6 & 9174 & 941 \\
\hline 2009 & $401(8.61)$ & 64.7 & 16 & 42.4 & 36.1 & 41.2 & 9599 & 987 \\
\hline 2010 & $373(7.78)$ & 55 & 19.2 & 40 & 25.4 & 37.6 & 8986 & 906 \\
\hline Total & $3028(9.1)$ & 72.1 & 16.2 & 45.7 & 42.2 & 45.1 & 73874 & 1100 \\
\hline
\end{tabular}

${ }^{\mathrm{a}}$ Values are expressed as No. (\%).

Among all deceased, $82.7 \%$ were men (male/female ratio, 4.8:1). This gender difference in every year is statistically significant $(\mathrm{P}<0.05)$. In 2004 , the road traffic fatality rate in the male population was 77.9 per 100,000 , which decreased to 55 in 2010. In the female population, however, this number increased, from 14.8 in 2004 to 19.2 in 2010 (Table 1). In other words, the male-to-female ratio decreased from 5.26 to 3.56 in this period. The trends in road traffic fatalities for each sex are shown in Figure 2.

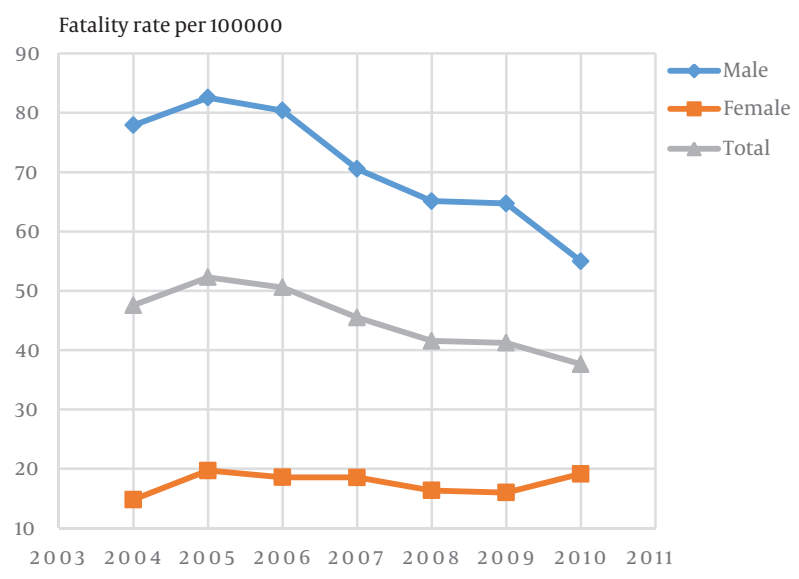

Figure 2. Trends in Road Fatality Rate Per 100,000 in Each Sex Over the Seven-Year Period From 2004 to 2010 in Yazd Province, Iran

About $83 \%$ of the deceased lived in urban areas (urban to rural ratio, 4.7:1). Over the course of the study period, the decrease in the fatality rate per 100,000 people in rural areas (from 49.7 to 25.4) was more remarkable than that of urban areas (from 47.0 to 40.0 ) (Table 1 ).
Investigation of the trend in road traffic deaths by month reveals an interesting pattern. Road traffic deaths peak during the summer. The fewest road traffic deaths occur in the winter $(\mathrm{P}<0.001)$. In our monthly analysis, after a low rate in the first months of winter, the number of death events began to rise in March and peaked in September. The differences in the number of deaths between seasons and months were statistically significant $(\mathrm{P}<0.001)$ (Table 2).

Total YLL in our study was 73,875 over this seven-year period (60,337 and 13,489 for men and women respectively). This indicator decreased from 11,122 in 2004 to 8,986 in 2010. The highest YLL (12434 years) was seen in 2005. YLL values for all years are shown in Table 1. The highest YLLs were in age groups of 20-24, 15 - 19 and 25 - 29 respectively. The lowest male-to-female ratio was in the age groups of 0 -4 and 5 - 9 years (male/female: 1.22 and 1.9); this ratio rises sharply (to 10.91) in the 15 - 19 year old age group (Figure 3).

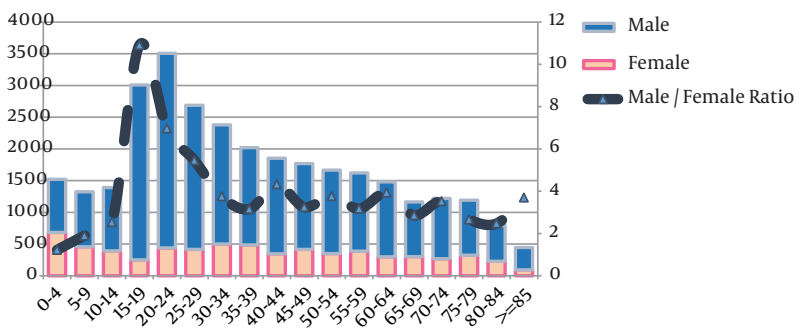

Figure 3. Years of lost life and male-to-female ratio classified by age group in Yazd Province, Iran, over the seven-year study period, 2004-2010 
Table 2. Road Traffic Deaths Classified by Season and Month Over the Seven-Year Study Period (2004 - 2010) in Yazd Province, Iran

\begin{tabular}{|cl|}
\hline Road Traffic Deaths & No. $(\%)$ \\
\hline Season of event $^{\mathbf{a}}$ & \\
\hline Spring & $835(27.4)$ \\
\hline Summer & $863(28.4)$ \\
\hline Autumn & $746(24.5)$ \\
\hline Winter & $584(19.2)$ \\
\hline Month of event ${ }^{\text {b }}$ & \\
\hline January & $195(6.4)$ \\
\hline February & $164(5.4)$ \\
\hline March & $262(8.6)$ \\
\hline April & $261(8.6)$ \\
\hline May & $270(8.9)$ \\
\hline June & $259(8.5)$ \\
\hline July & $295(9.7)$ \\
\hline August & $284(9.3)$ \\
\hline September & $301(9.9)$ \\
\hline October & $259(8.5)$ \\
\hline November & $242(8.0)$ \\
\hline December & $236(7.8)$ \\
\hline
\end{tabular}

${ }^{\mathrm{a}}$ Chi square: $62.58 ; \mathrm{P}<0.001$.

${ }^{\mathrm{b}}$ Chi square: $68.26 ; \mathrm{P}<0.001$

\section{Discussion}

The highest rate of motor vehicle ownership per family in Iran is seen in Yazd province according to the statistical center of Iran (12). This confirms the necessity of specific and appropriate preventive measures on the basis of reliable studies. This research is a descriptive study that investigated road traffic deaths in Yazd and found significant trends in death rates in association with gender, age group, place of residence and month/season of traffic event. Our analysis included the more than 3,000 deaths and 73,000 YLL due to road traffic accidents reported in Yazd province between 2004 to 2010 .

The proportion of deaths in Yazd province due to road traffic accidents decreased from $9.29 \%$ in 2004 to $7.78 \%$ in 2010. The road fatality rate in this period also decreased from 47.6 to 37.6 per 100,000 . The overall road traffic fatality rate in Iran experienced a similar decrease during this time (from 38.2 to 31.1). This reduction can mainly be attributed to new, stricter police regulations all over the country. The main interventions in 2005 were laws making the wearing of seat belts and motorcycle helmets mandatory, intensification of traffic laws, and production of mass media educational programs $(8,9,15)$.

A comparison between the road fatality rates of Yazd and Iran and global reports reveals a remarkable difference. Despite the considerable decrease of traffic deaths in Yazd, the total number compared to Iran (32.9), eastern mediterranean region (21.3), and the world (18.03) is still unacceptably high $(7,9,16)$. Only 6 countries, including Iran, reported a road accident mortality rate of more than 38 per 100,000 people in 2007 , and the number of these countries dropped to 3 (including Iran) in $2010(2,7)$.

The higher road fatality rate in our study may be partially explained by the type and number of vehicles in this area. Due to a lack of safety equipment in two-wheeled vehicles, especially motorcycles, the death risk for their drivers compared to car passengers is much higher $(17,18)$. According to the 2011 census in Iran, the prevalence of car ownership in Yazd is 58\%, which is much higher than the rate in the whole country (42\%). But, the prevalence of motorcycle ownership is even higher value compared to the rest of the country (57\% vs. 22\%) (12). So both the amount and type of vehicles in this area may be partly responsible for the higher rate of road traffic deaths in our study. These different rates may be attributed to cultural reasons in addition to socioeconomic status.

In our investigation period, $82.7 \%$ of all people who died in road traffic events were men, and this statistically significant gender difference was seen every year $(\mathrm{P}$ $<0.005)$. In the eastern mediterranean region $75 \%$ of road traffic casualties are men (male/female ratio, 3:1) (7). Male dominance in road traffic deaths has been seen in similar studies in Yazd (19), other provinces of Iran (9, 20-22), and other countries $(7,15,23-25)$. This gender difference can be attributed to the increased susceptibility and exposure of men due to specific occupational, cultural, and social properties.

In spite of the reduction of the road traffic fatality rate per 100,000 men (from 77.9 to 68.5), which is consistent with the trend seen in the national data (from 55 to 52.3), the road traffic fatality rate per 100,000 in the female population increased from 14.8 to 19.2 over our study period. Other studies in Iran showed an increasing (10) or constant (9) rate the in female population after 2005. Probable causes of this inconsistency are the increasing involvement of women in activities outside the home and increased numbers of female drivers in local populations (10, 20).

The majority of road traffic deaths (57\%) occur in people aged 15 - 44, which is the active age group for national productivity and economic growth. In the eastern mediterranean region $60 \%$ of road traffic deaths occur in this age group (7). The most affected age groups in other studies conducted in India (ages 18 - 37) (26), China (18 - 30) 
(27), and Thailand (16 - 25) (28) are similar to the findings of our study (20-24). This is probably due to the higher involvement in road transportation, greater tendency toward high-risk activities and lower willingness to follow the traffic rules in these age groups.

The overall number of deaths in older people is less than that of youths; proportionally, though, the highest road traffic fatality rate per 100,000 is seen in elderly people. This is consistent with other studies in Iran $(29,30)$. Another study in China reported a fatality rate in people above 65 twice as high as the rate in younger people (31). The smaller total population of elderly people, in addition to their reduced physical tolerance for injury, can explain this higher age-specific mortality rate.

In investigation of seasonal and monthly time trends, the most deaths occurred in summer, and especially September $(\mathrm{P}<0.001)$. This pattern is also seen in other studies in Iran $(10,32,33)$. This trend in traffic deaths is attributed to an increased level of road travel by car in these times, and highlights the need for more preventive measures in this period of the year. In a study in China, more fatalities due to road accidents are reported in autumn and winter (34). This may be because of the different cultural traditions and climates in each region, which determine the season of most road travels.

As is shown in Table 1, incidents of road traffic deaths in the first years of our investigation were a little higher in rural areas. Despite the smaller amount of vehicles in rural areas, the risk of road traffic deaths in these areas still remains high. This disparity in road traffic death rates can be explained by the lack of safety on rural roads, lower level of expertise of rural drivers, and lack of safety in farm vehicles used for transportation in rural areas. More rural road traffic deaths are also reported in studies done in China (34) and Ireland (35). However, in our study the trend of reductions in road traffic deaths during the years under investigation was more considerable in rural areas and resulted in less road fatalities in the final years of our study (from 49.7 to 25.4 [rural] vs. 47 to 40 [urban]).

Our study did have some limitations. The national census, which was the basis for the estimation of population by health centers, was conducted in 1996, 2006, and 2011. The population between these years has been estimated by local data on births and deaths by health centers. Lack of exact information about annual immigration is a limitation in the estimation of the population in these years. Also, we did not analyze the deaths per 10,000 vehicles index.

\subsection{Conclusion}

A decrease in the road traffic fatality rate after 2005 can be attributed to effective interventions by legislative orga- nizations, police and mass media. In spite of the reduction in road traffic deaths, Yazd province has one of the highest road traffic fatality rates in Iran and world. These findings can serve as a basis for health care professionals and policymakers to implement more preventive measures, especially during summer vacations. Regarding the increasing female road traffic fatality rate, we also suggest that future studies about patterns of risk-taking behaviors in female population be conducted and specific interventions be developed to counter these behaviors.

Analysis of the causes of road traffic deaths needs other studies addressing safety indices of vehicles and roads, velocity of vehicles, and individual risk-taking behaviors such as consumption of alcohol and drugs and mobile phone use.

\section{Acknowledgments}

The authors wish to acknowledge the cooperation and efforts of the death registries and Yazd Health Center for supplying our data. We also thank the staff of local health facilities who reported their cases to the health center of Yazd province.

\section{Footnote}

Authors' Contribution: Mohsen Mirzaei: study concept and design, analysis and interpretation of data, statistical analyses, study supervision, and administrative support; Mojtaba Mirzaei: analysis and interpretation of data, drafting of the manuscript, statistical analyses technical and material support; Mahboobahsadat Mirzadeh: critical revision of the manuscript for important intellectual content; Hossein Shogaei Far: acquisition of data.

\section{References}

1. Al-Kharusi W. Update on road traffic crashes: progress in the Middle East. Clin Orthop Relat Res. 2008;466(10):2457-64. doi: 10.1007/s11999008-0439-5. [PubMed: 18704613].

2. World Health Organization. Global status report on road safety: time for action. Geneva: World Health Organization; 2009. p. 301.

3. Hazen A, Ehiri JE. Road traffic injuries: hidden epidemic in less developed countries. J Natl Med Assoc. 2006;98(1):73-82. [PubMed: 16532982].

4. Hyder AA, Amach OH, Garg N, Labinjo MT. Estimating the burden of road traffic injuries among children and adolescents in urban South Asia. Health Policy. 2006;77(2):129-39. doi: 10.1016/j.healthpol.2005.07.008. [PubMed: 16112772].

5. Naci H, Chisholm D, Baker TD. Distribution of road traffic deaths by road user group: a global comparison. Inj Prev. 2009;15(1):55-9. doi: 10.1136/ip.2008.018721. [PubMed:19190278].

6. Akbari ME, Naghavi M, Soori H. Epidemiology of deaths from injuries in the Islamic Republic of Iran. East Mediterr Health J. 2006;12(3-4):38290. [PubMed: 17037707]. 
7. World Health Organization. Global status report on road safety 2013 : supporting a decade of action. Geneva: World Health Organization; 2013.

8. Soori H, Royanian M, Zali AR, Movahedinejad A. Road traffic injuries in Iran: the role of interventions implemented by traffic police. Traffic Inj Prev. 2009;10(4):375-8. doi: 10.1080/15389580902972579. [PubMed: 19593716].

9. Bahadorimonfared A, Soori H, Mehrabi Y, Delpisheh A, Esmaili A, Salehi M, et al. Trends of fatal road traffic injuries in Iran (20042011). PLoS One. 2013;8(5):eee65198. doi:10.1371/journal.pone.0065198. [PubMed: 23724132].

10. Hasanzadeh J, Moradinazar M, Najafi F, Ahmadi-Jouybary T. Trends of Mortality of Road Traffic Accidents in Fars Province, Southern Iran, 2004 - 2010. Iran J Public Health. 2014;43(9):1259-65. [PubMed: 26175980].

11. Bhalla K, Naghavi M, Shahraz S, Bartels D, Murray CJ. Building national estimates of the burden of road traffic injuries in developing countries from all available data sources: Iran. Inj Prev. 2009;15(3):150-6. doi:10.1136/ip.2008.020826. [PubMed: 19494093].

12. Statistical Center of Iran . Families classified by ownership of motorcycles , privatec cars and compuetrs in place of residence. National Census; 2011.

13. Mathers C, Vos T, Lopez A, Salomon J, Ezzati M. National Burden of Disease Studies: A Practical Guide. 2 ed. Geneva: World Health Organization; 2011.

14. Mathers CD, Bernard C, Iburg KM, Inoue M, Ma Fat D, Shibuya K, et al. Global burden of disease in 2002: data sources, methods and results. Geneva: World Health Organization; 2003.

15. Rasouli MR, Nouri M, Zarei MR, Saadat S, Rahimi-Movaghar V.Comparison of road traffic fatalities and injuries in Iran with other countries. Chin J Traumatol. 2008;11(3):131-4. [PubMed:18507940].

16. Bachani AM, Zhang XJ, Allen KA, Hyder AA. Injuries and violence in the Eastern Mediterranean Region: a review of the health, economic and social burden. East Mediterr Health J. 2014;20(10):643-52. [PubMed: 25356696].

17. Lin MR, Kraus JF. A review of risk factors and patterns of motorcycle injuries. Accid Anal Prev. 2009;41(4):710-22. doi: 10.1016/j.aap.2009.03.010. [PubMed: 19540959].

18. Vafaee-Najar A, Esmaeili H, Ibrahimipour H, Dehnavieh R, Nozadi MS. Motorcycle fatal accidents in khorasan razavi province, iran. Iran J Public Health. 2010;39(2):95-101. [PubMed: 23113012].

19. Moharamzad Y, Taghipour H, Hodjati Firoozabadi N, Hodjati Firoozabadi A, Hashemzadeh M, Mirjalili M, et al. Mortality pattern according to autopsy findings among traffic accident victims in Yazd, Iran. Chin J Traumatol. 2008;11(6):329-34. [PubMed: 19032846].

20. Roudsari BS, Sharzei K, Zargar M. Sex and age distribution in transport-related injuries in Tehran. Accid Anal Prev. 2004;36(3):3918. doi: 10.1016/S0001-4575(03)00032-0. [PubMed: 15003584].

21. Fazel MR, Fakharian E, Mahdian M, Mohammadzadeh M, Salehfard L, Ramezani M. Demographic Profiles of Adult Trauma During a 5 Year Period (2007-2011) in Kashan, IR Iran. Arch Trauma Res. 2012;1(2):63-6. doi: 10.5812/atr.6770. [PubMed: 24396745].
22. Mahdian M, Sehat M, Fazel MR, Moraveji A, Mohammadzadeh M. Epidemiology of Urban Traffic Accident Victims Hospitalized More Than 24 Hours in a Level III Trauma Center, Kashan County, Iran, During 2012-2013. Arch Trauma Res. 2015;4(2):eee28465. doi: 10.5812/atr.4(2)2015.28465. [PubMed: 26101765].

23. Ziyab AH, Akhtar S. Incidence and trend of road traffic injuries and related deaths in Kuwait: 2000-2009. Injury. 2012;43(12):2018-22. doi 10.1016/j.injury.2011.09.023. [PubMed: 22019357].

24. Ngo AD, Rao C, Hoa NP, Hoy DG, Trang KT, Hill PS. Road traffic related mortality in Vietnam: evidence for policy from a national sample mortality surveillance system. BMC Public Health. 2012;12:561. doi: 10.1186/1471-2458-12-561. [PubMed: 22838959].

25. Alghnam S, Palta M, Hamedani A, Remington PL, Alkelya M, Albedah $\mathrm{K}$, et al. In-hospital mortality among patients injured in motor vehicle crashes in a Saudi Arabian hospital relative to large U.S. trauma centers. Inj Epidemiol. 2014;1(1):21. doi: 10.1186/s40621-0140021-4. [PubMed: 26613073].

26. Kumar A, Lalwani S, Agrawal D, Rautji R, Dogra T. Fatal road traffic accidents and their relationship with head injuries: An epidemiological survey of five years. Indian J Neurotrauma. 2008;5(2):63-7.

27. Zhou JH, Zhao XC, Wang ZG, Zhu PF, Jian HG, Liu DW, et al. The analysis of epidemiological characteristics of road traffic crashes in a mountain city in western China. Chin JTraumatol. 2003;6(6):355-8. [PubMed: 14642056].

28. Suriyawongpaisal P, Kanchanasut S. Road traffic injuries in Thailand: trends, selected underlying determinants and status of intervention. Inj Control Saf Promot. 2003;10(1-2):95-104. doi: 10.1076/icsp.10.1.95.14110. [PubMed: 12772492].

29. Mehmandar M, Soori H, Amiri M, Norouzirad R, Khabzkhoob M. Risk factors for fatal and nonfatal road crashes in iran. Iran Red Crescent Med J. 2014;16(8):eee10016. doi: 10.5812/ircmj.10016. [PubMed: 25389468].

30. Mahdian M, Fazel MR, Sehat M, Mohammadzadeh M, Akbari H. Years of Life Lost and Mortality Rate Due to Road Traffic Injuries in Kashan Region, Iran, During 2012-2013. Biosci Biotech Res Asia. ;12:741-6.

31. Lee WY, Cameron PA, Bailey MJ. Road traffic injuries in the elderly. Emerg Med J. 2006;23(1):42-6. [PubMed:16381081].

32. Heydari ST, Hoseinzadeh A, Sarikhani Y, Hedjazi A, Zarenezhad M, Moafian G, et al. Time analysis of fatal traffic accidents in Fars Province of Iran. Chin J Traumatol. 2013;16(2):84-8. [PubMed: 23540895].

33. Yadollahi M, Paydar S, Sabetianfard Jahromi G, Khalili H, Etemadi S, Abbasi $\mathrm{H}$, et al. Types and causalities in dead patients due to traumatic injuries. Arch Trauma Res. 2015;4(1):eee26028. doi: 10.5812/atr.26028. [PubMed: 25798419].

34. Zhang X, Yao H, Hu G, Cui M, Gu Y, Xiang H. Basic characteristics of road traffic deaths in china. Iran J Public Health. 2013;42(1):7-15. [PubMed: 23515114].

35. Boland M, Staines A, Fitzpatrick P, Scallan E. Urban-rural variation in mortality and hospital admission rates for unintentional injury in Ireland. Inj Prev. 2005;11(1):38-42. doi: 10.1136/ip.2004.005371. [PubMed: 15691988]. 